\title{
INTEGRATION OF HEALTH, SAFETY AND ENVIRONMENTAL PRINCIPLES INTO INDUSTRIAL PROJECT MANAGEMENT
}

\author{
Emilija Kozhovska \\ LTH Castings, Ohrid, Macedonia
}

\begin{abstract}
Planning and implementation of health, safety and environmental (HSE) principles in early stage of industrial projects can prevent many negative consequences such as poor HSE and quality outcomes, schedule delays, reduced productivity and cost increases. Industrial projects often contain high risk level and uncertainty that can lead to inappropriate decision - making. Such risk can manifest itself as threat affecting human life or the environment. The focus of this paper includes legislation and regulations, management systems, HSE analysis throughout project life cycle and efforts to integrate HSE risk management to industrial safety practices. This article also puts into perspective the complexity of the challenge of integrating HSE into industrial project management.
\end{abstract}

Key words: Project management, health, safety and environment, industry.

\section{INTRODUCTION}

Most of industrial companies use the concept of project management to plan, organize, execute, and control the progress of their projects in order to achieve satisfactory completion. In fact, the main reasons for project management are to satisfy the stakeholders within a specified timescale, scope, budget, and specified quality (Althaqafi \& Elssy, 2015). However, occupational fatalities, injuries and diseases also contribute to variability of resource, which increases project risk. Such risk can manifest itself in occupational accidents, damage to the environment, reduced productivity, nonconformance of quality standards and time overruns, and ultimately in an increase in the costs of project and delays of schedule (Smallwood \& Venter, 2002). Taking into account that the elimination of occupational and environmental risks contributes to the success of industrial projects, it's always more advantageous when introduced at the definition stage of a project, but also when all involved parts remain mindful of it at all stages to the completion of a project (Badri, Gbodossou, \& Nadeau, 2012). Integration of HSE principles into project management involves challenges that must be approached using a variety of disciplines (technological, managerial and sociological) (Badri, 2015).

\section{METHODOLOGY}

This study is qualitative; it uses data in the form of normative acts, regulations, documents and data from literature. The basic data collectionincludes literature covering aspects of HSE, risk management and project management.

Firstly, the recent literature was reviewed and summarized briefly the extent to which HSE risks are taken into account in the project management and industrial practices.

In order to achieve the objective of the research, I began by narrowing the focus to the principal problematic aspects of integrating HSE into risk management in the context of industrial projects, based on a systematic examination of the literature and consider interactions that also appear to be aspects of the problem. Than the literature was selected and structured the examination of the question surrounding the integration of HSE risks into project management and industrial practices.

Corresponding author. Email: emilija_kozovska@yahoo.com

ISSN 2560-4961(online)

(C) 2018 IPMA Serbia

doi: 10.18485/epmj.2018.8.1.5 
In addition, integration of HSE risks into project management differs greatly from one industrial sector to another. In part, these differences are mainly due to risk acceptability, regulations differ greatly among different countries, organizations, and companies, maturity of project management standards and use of management systems.

Finally, the review of literature is discussed, regarding the state of the HSE integration into industrial projects, supported with recommendations.

\section{THE CONCEPT OF SAFETY}

Alli (2008) gives the following definition of occupational safety: “...is generally defined as the science of the anticipation, recognition, evaluation and control of hazards arising in or from the workplace that could impair the health and well-being of workers, taking into account the possible impact on the surrounding communities and the general environment".

From a health \& safety standpoint, it involves creating organized efforts and procedures for identifying workplace hazards and reducing accidents and exposure to harmful situations and substances.

From an environmental standpoint, it involves creating a systematic approach to complying with environmental regulations and protect natural environment from pollution and destruction.

It is now possible make an introduction to the concept of HSE in general terms. Simply put, HSE management aims to predict and reduce the probability of accidents or hazards with implications to humans and environment, with other words:

- Protecting the employees - mental and physical health by preventing workingrelated accidents, injuries, and diseases, and providing a safe working area; and
- Paying attention to the nature and the environment by prohibition or limiting the usage of harmful materials to the environment, reducing environmental pollutants, and using recourses feasibly.

On one hand, we have a "health and safety" component, that refers to predicting and minimizing the probability of hazards, that in other words means improving safety of humans. On the other hand, we have the environment, which can imply to definitions the working environment for people, and overall community in the sense of the influence to nature and environment by company's operations.

\section{PROJECT MANAGEMENT}

Association for Project Management (APM Body of Knowledge, 2000) defines a project management as an endeavor in which human material and financial resources are organized in a novel way to deliver a unique scope of work of given specification often within constraints of cost and time to achieve beneficial changes defined by quantitative and qualitative objectives.

The Project Management Institute (A Guide to the Project Management Body of Knowledge, 2008) defines project management as application of knowledge, tools and techniques to meet project requirements.

The project management has a number of stages called life cycles, with each stage integral to the overall success of the project. Lifecycles vary depending on the industrial sector, the technology used and sometimes on the uniqueness of the organization (Badri, 2015).

Nevertheless, in the majority of cases, the project life-cycle follows these usual stages Figure 1 illustrates the lifecycle of a typical project comprising four phases: 


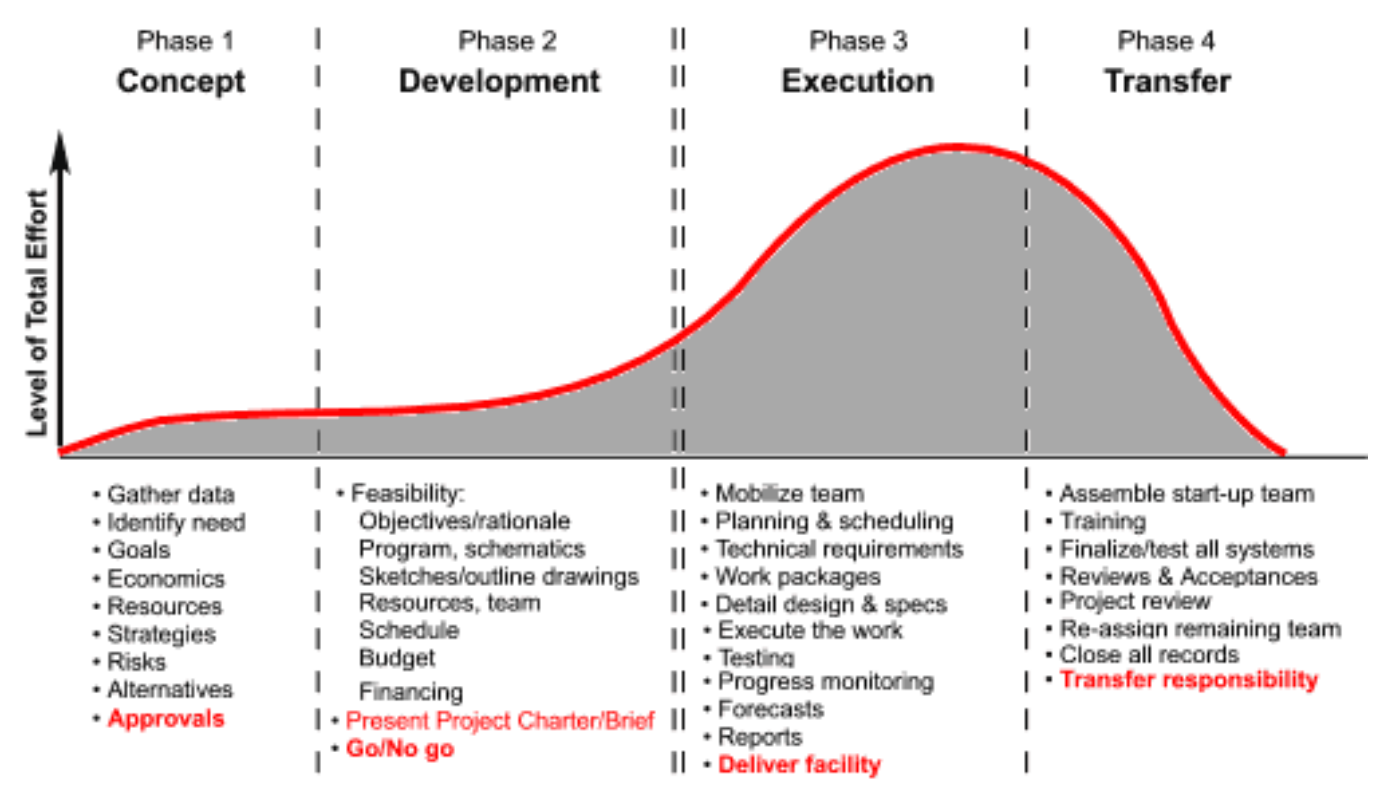

Figure 1: Project Lifecycle (Adams \& Barndt, 1978)

1. Concept or Project initiation phase - This is where the project's value and feasibility are analyzed.

2. Development or Project planning phase - project plan includes directions for obtaining resources, acquiring financing and procuring required materials. The project plan gives the team direction for producing quality outputs, handling risk, creating acceptance, communicating benefits to stakeholders and managing suppliers (Bisk Education, 2015).

3. Project execution and monitoring phase the most important phase during which are prepared deliverables, monitoring and control the evolution of the project

4. Completion - Project closure phase -This phase represents the completed project i.e. when project team deliver the finished project to the customer, communicating completion to stakeholders and releasing resources to other projects. This important step in the project lifecycle allows the team to evaluate and document the project and analyze project failures and weaknesses, as well successes so that improvements can be made for future projects.

The management of a project is often subject to the influence of several factors, both endogenous (internal) and exogenous (external to the project) (Badri, 2015). These factors include (Perminova, 2011; Vidal \& Marle, 2008; Hussain \& Wearne, 2005):
- Internal parameters as technical project complexity (scale, duration, budget, number of activities);

- Internal organization factors (diversity of teams, experience, communication skills, geographical location of actors, management methods and tools used, policies, manuals etc.);

- External parameters (customer, stakeholders, number of suppliers or sub-contractors, etc.);

These factors make the achieving of objectives more complex by imposing constraints on essential activities (e.g., risk management) for undeterminable periods of time (Hussain \& Wearne, 2005).

In projects, these risks are overcome by proactively employing project manager's and team members combined knowledge, judgment based on experience and creativity (Maytorena, Winch, Freeman, \& Kiely, 2007).

\section{HSE LAWS, REGULATIONS AND MANAGEMENT SYSTEMS}

Institutionally, the management of HSE issues is, first of all, represented by set of governmental bodies who are responsible for HSE in a given country, and therefore in a variety of industrial activities (Paramonov, 2016). Than HSE is regulated by a set of legislative requirements, laws, regulations, 
guidelines, recommendations and criteria published by an authorized institution. All these various forms can be referred to as an HSE regulatory environment.

History has shown that without strict laws and regulations, the companies have a difficulty of changing their practices and perceptions in the absence of tangible economic data. On the other hand, we can note that despite the willingness of companies, the support of validated and published solutions, the application of laws and regulations, the dangers are still occurring and sometimes they cause fatal accidents (Shikdar \& Sawaqed, 2003). However, protecting employees and environment is more than simply regulatory compliance.

Regarding international standards, occupational health and safety management systems are often used in conjunction with environmental management systems. This is because ISO 14001:2015 - Environmental management systems - Requirements with guidance for use and OHSAS 18001, which has served as the primary framework for an occupational health and safety management system prior to the release of ISO 45001:2018, while varying greatly in purpose, are highly comparable in terms of primary elements like policies, objectives, and preventive action (Kelechava, 2018).

Also, the aim of Annex SL (ISO/IEC Directives, 2016) is to enhance the consistency and alignment of ISO management system standards by providing a unifying and agreed high level structure, identical core text and common terms and core definitions. This will help organizations that choose to operate a single (sometimes called "integrated") management system. An interaction of elements aims to incorporate and integrate all of the main requirements of an EMS and/or OHSMS to provide that all requirements have been met and to show the correlation between the following:

- Environmental aspects / OHS hazards and risks

- Objectives, targets and programs

- Legal and other requirements

- Performance indicators
- Operational controls

- Monitoring and measurement processes

- Corrective and preventive measures

Regarding occupational health and safety ISO has developed a new standard, ISO 45001:2018, Occupational health and safety management systems - Requirements. It provides governmental agencies, industry and other affected stakeholders with effective guidance in order to reduce this burden by providing a framework to improve employee safety, reduce workplace risks and create better, safer working conditions, in countries around the world (International Labour Organisation, 2018).

ISO management system standards (MSS) help organizations improve their performance by specifying repeatable steps that organizations consciously implement to achieve their goals and objectives, and to create an organizational culture that reflexively engages in a continuous cycle of self-evaluation, correction and improvement of operations and processes through heightened employee awareness and management leadership and commitment.

\section{INTEGRATING HSE RISK MANAGEMENT THROUGHOUT PROJECT LIFE CYCLE}

Risk analysis and risk assessment is viewed as a crucial step and plays major role in integration of HSE principles throughout project life cycle. Implementation of early HSE analysis allows identifying project - specific HSE challenges and to select appropriate risk identification and control methods (Integrate Health, Safety and Environment into Engineering Projects, 2013). HSE risks may be those which are directly linked with the health and safety of workers and staff of project site. Moreover, those risks may also adversely impact on environment. HSE risk comprises the threat of accidents, personal injuries, occupational illness and environmental damage. Risk is directly proportional to probability and consequence/ impact.

Risk $=\mathrm{f}$ (probability, consequence/impact on Health, Safety and Environment) (Mubin, Shah, \& Yunus, 2014) 
Risk assessment consists of risk identification, risk analysis (frequency evaluation + consequence evaluation), and risk evaluation (assessment of tolerability of risk to people, environment, assets and reputation by comparing risk level with the relevant tolerability criteria) (Paramonov, 2016). In order to interpret HSE risk means of measurement of risk are required, such as: injuries/fatalities/ occupational illness per year, emissions in the water, air, soil, financial losses per year.

Qualitative assessment remains essential in prioritizing HSE risk (e.g. collecting data, modeling techniques and expert opinion). The purpose of this evaluation is to prioritize risks in terms of the likelihood of their occurrence and their impact on the project goals. Qualitative assessment is often supplemented by a quantitative review to the extent possible. Subsequent risk assessment, the process is completed by adopting a risk control action plan integrated into the project management process as an indicator measuring the effectiveness of the approach (Badri, et al., 2012; A Guide to the Project Management Body of Knowledge, 2008). Risk is also directly proportional to the hazard but indirectly proportional to the protection and preventive measures. However, with proper assessment and mitigation techniques risk can be reduce to an acceptable level.

In order to identify and manage HSE risks associated with a project, a company requires involvement and participation of the project manager, the risk management team, the project team members, customers, experts, end users, stakeholders and the specialists in risk analysis.

Finally, integration of HSE in engineering project management depends on communication, culture, worker attitudes, motivation, skill, health and physical condition (Gibb, Haslam, Gyi, Hide, \& Duff, 2006). Other risk factors are linked to the management of projects, the culture prevailing with respect to safety, environment and risk management and the economic climate in which a company operates. However, implementation of measures into the management of industrial projects, for example, the level of care required at the design and all stages of project lifecycle and the degree of commitment on the part of the companies involved. Figure 2 illustrates integration of HSE risk management into project management.

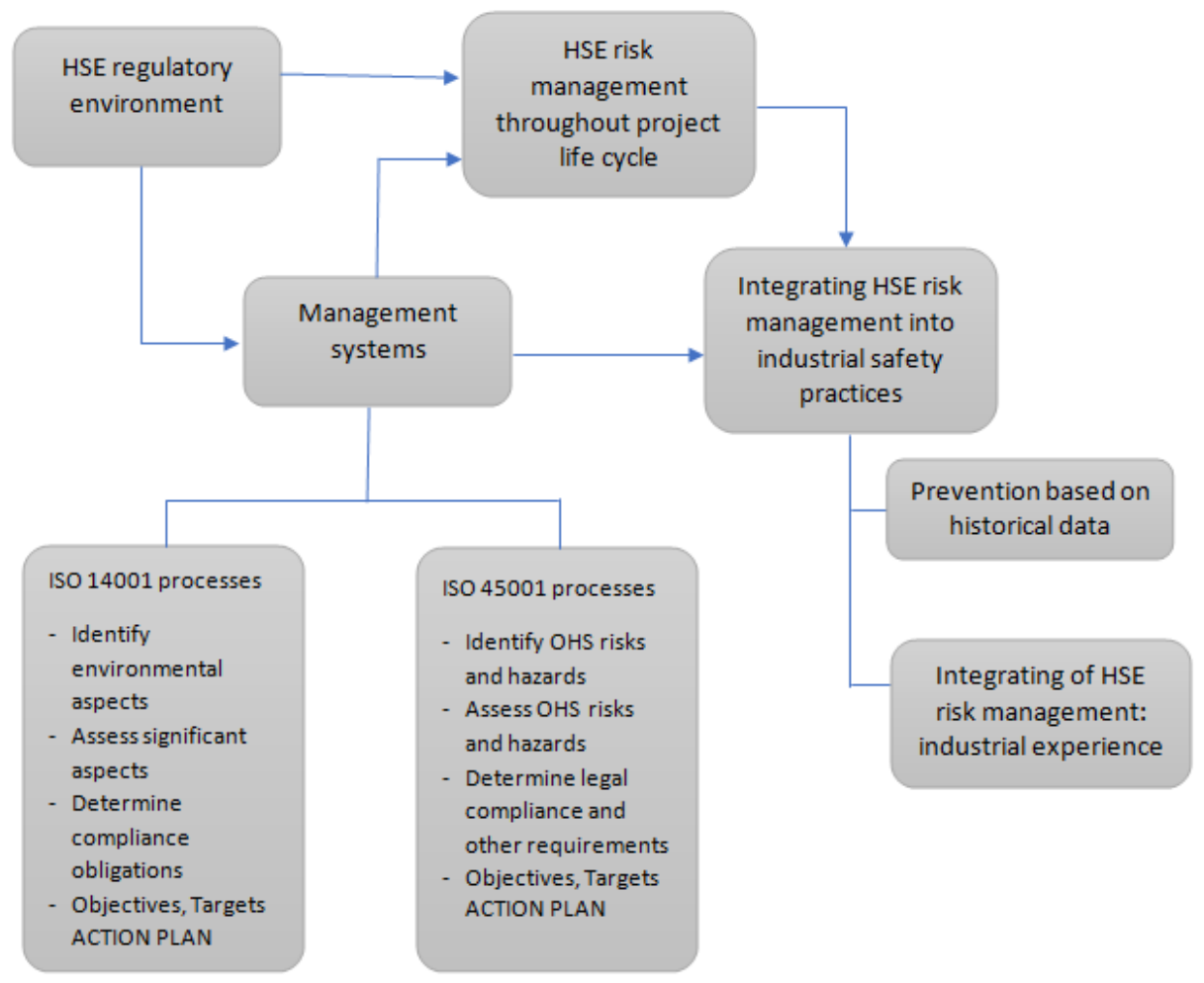

Figure 2: Integration of HSE Risk Management into Project Management (own illustration based on Badri, et al., 2012) 


\section{DISCUSSION}

This review has examined the recent literature and has summarized briefly the extent to which HSE risks are taken into account in the project management and industrial safety practices.

Badri, et al., (2012) emphasized that injuries and accidents continuously happen and cause human distress, social problems, environmental issues and cost increases. They also point out that the accidents in project lifecycle are closely connected with the low educational level of workers, communication problems, organizational approach, and insufficient commitment from top managementand lack of safety culture.

Saurin, Formoso, \& Guimarães, (2004) point out that having a systematic integration of safety management into the core processes of project management (such as design, cost management, procurement,) is essential to improve occupational health and safety.

Another study (Integrate Health, Safety and Environment into Engineering Projects, 2013) found that early planning and implementation of HSE principles during design phase are crucial in order to minimize risks to employees and the environment throughout the entire lifecycle of project. Moreover, early application of HSE fundamentals also provides an opportunity to integrate inherently safer design principles. Furthermore, despite accident prevention strategies, coordination and communication, and innovative HSE initiatives are required to enhance project health and safety performance.

In general, the researchers are oriented towards the study of the economic impact of HSE issues. These losses could be evaluated by the costs of compensation and insurance, the company's reputation and ability to retain its skilled workforce. Moreover, the lack of safety commitment may cause huge losses in financial terms, in terms of company's image resulting with loss of stakeholders and clients, and cause increasing of labor conflict. The primary goal of the company is to assure safety of workers and to people located in the area of operations, and prevent any possible accidents, injuries and effects of health. In addition, environmental pollution and contamination shall be a part of safety evaluations.

In order to reduce HSE incidents, industrial projects should be built around a corporate HSE management system fostered and supported by corporate leadership. Hence, having a widespread good practice and culture of HSE can be considered a common goal for the common good: to make sure the activities are safe and not dangerous for the environment as well as humanity in general (Paramonov, 2016).

\section{CONCLUSION}

The foundation of health, safety and environmental success is commitment by everyone involved in the project to their personal and collective HSE outcomes. The study basically demonstrates the need to consider HSE risks and plan adequate recourses and funding to the project risk management team in organizations, in order to avoid accidents that threaten them.

Top Management must provide leadership by integrating HSE activities into project phases, by initiating meetings where complete project team can contribute, and by seeking open participation, along with efforts of a concentration on HSE awareness and culture. Industrial projects may ultimately involve by several to hundreds or thousands of people in engineering, quality, procurement and other sectors, as well as the subsequent commissioning and startup. Each discipline and sector can considerably contribute to the overall safety of industrial project by applying the best practices, which involves all members of the project team in cooperative and dedicate efforts. Attempts are underway to integrate HSE principles within a framework of continuous improvement.

However the integration of HSE principles into project management is not systematic in all industrial fields despite the enhancing and improving legal requirements and management systems. 
Furthermore, HSE management is integral and fundamental component for the business success and growth, and profit of the company. It is more than evident, because any failure in this domain will bring irreversible harm to the reputation, and consequently to the organization's incomes.

\section{REFERENCES}

Adams, J. R., \& Barndt, S. E. (1978). Organizational Life Cycle Implications for Major Projects. Project Management Quarterly, Vol. IX, No. 4, pp. 32-39.

A Guide to the Project Management Body of Knowledge (PMBOK Guide). (2008). 4th ed. Project Management Institute. Newtown Square, PA

Althaqafi, T., \& Elssy, B. (2015). Integrating Occupational Health and Safety Systems into a Project Management System. International Journal of Research in Management \& Business Studies IJRMBS

Alli, B. O. (2008). Fundamental Principles of Occupational Health and Safety. Second Edition, International Labour Organization

APM Body of Knowledge. (2000). Association for Project Management

Badri, A., Gbodossou, A., \& Nadeau, S. (2012). Occupational health and safety risks: Towards the integration into project management. Safety Science Journal

Badri, A. (2015). The Challenge of Integrating OHS into Industrial Project Risk Management: Proposal of a Methodological Approach to Guide Future Research (Case of Mining Projects in Quebec, Canada). Minerals Journal

Bisk Education. (2015). On Behalf of Villanova University, Five Phases of the Project Management Lifecycle. Available at

https://www.villanovau.com/resources/pr oject-management/5-phases-projectmanagement-lifecycle/\#.WtTvQi5ubDc

Gibb, A., Haslam, R., Gyi, D., Hide, S., \& Duff, R. (2006). What causes accidents? Hide and Duff, 46-50.

Hussain, R., \& Wearne, S. (2005). Problems and Needs of Project Management in the Process and Other Industries. Chem. Eng. Res., 83, pp. 372-378.
Integrate Health, Safety and Environment into Engineering Projects. (2013). American Institute of Chemical Engineers

International Labour Organisation. (2018). available at https://www.iso.org/iso45001-occupational-health-andsafety.html

ISO/IEC Directives Part 1, Consolidated ISO Supplement - Procedures specific to ISO, Annex SL, Seventh edition. (2016).

Kelechava, B. (2018). Integrating ISO 45001 and ISO 14001: Occupational Health and Safety and Environmental Management. American National Standards Institute

Maytorena, E., Winch, G. M., Freeman, J., \& Kiely, T. (2007). The Influence of Experience and Information Search Styles on Project Risk Identification Performance. IEEE Transactions On Engineering Management, 54, pp. 315326.

Mubin, S., Shah, U. T., \& Yunus, S. (2014). HSE Risk Assessment of Multistorey Building Project at Lahore, Asian Academic Research, Journal of Social Science \& Humanities

Paramonov, S. (2016). Managing HSE risks in the Barents Sea offshore projects: approaches of Norwegian regulators and Eni Norge in Goliat operations

Perminova, O. (2011). Managing Uncertainty in Projects. Åbo Akademi University Press

Shikdar, A. A., \& Sawaqed, N. M. (2003). Worker productivity and occupational health and safety issues in selected industries. Computers and Industrial Engineering, 45, pp. 563-572.

Saurin, T. A., Formoso, C. T., \& Guimarães, M. (2004). Safety and production: an integrated planning and control model. Construction Management \& Economics, 22(2), pp.159-169.

Smallwood, J., \& Venter, D. (2002). The influence of project managers on construction health and safety in South Africa. The Australian Journal of Construction Economics and Building

Vidal, L. A., \& Marle, F. (2008). Understanding project complexity: Implications on project management. Kybernetes, 37, pp.10941110 . 